\title{
ОЦЕНКА РИСКА ВОЗДЕЙСТВИЯ ОПАСНЫХ ПРИРОДНЫХ ПРОЦЕССОВ НА ПОБЕРЕЖЬЕ ОСТРОВОВ РУССКИЙ И ШКОТА (ЗАЛИВ ПЕТРА ВЕЛИКОГО, ЯПОНСКОЕ МОРЕ)
}

\author{
Лебедев И.И. \\ Тихоокеанский институт географии ДВО РАН, г. Владивосток \\ Ilya.lebedev.1994@bk.ru
}

\begin{abstract}
Аннотация. В береговой зоне отмечается проявление наиболее опасных природных катастрофических событий. Изучение этой зоны необходимо для более верного выбора оптимального пути ее развития. Очень ограниченное число исследований концентрируются на оценке опасности аномальных природных процессов. В данной работе была выполнена балльная оценка потенциальной опасности воздействия аномальных природных процессов на береговую зону островов Русский и Шкота. Для этого была проведена типология берегов островов Русский и Шкота. Всего на о. Русский выделено четыре типа и двенадцать подтипов берегов. На о. Шкота было выявлено четыре типа и восемь подтипов берегов. На обоих островах были определены коэффициенты расчлененности берегов. Этот показатель равен отношению между длиной берега и геодезической линии, соединяющей концы участка берега. Рассмотрены особенности воздействия опасных природных процессов (цунами, штормовых нагонов, оползней, обвалов, абразии) на побережье островов Русский и Шкота. На обоих островах эти процессы распространены в полной мере. Цунами подвержено в основном восточное побережье островов, штормовые нагоны развиты на всем протяжении берегов островов, а оползни и обвалы распространены достаточно дисперсно на обоих островах. Используя балльную систему оценки от 1 до 3 , где 1 - это наличие процесса (его слабое проявление), 2 - среднее проявление, а 3 - потенциальная опасность (для оползней и обвалов), были выявлены наиболее опасные типы и подтипы берегов островов. На о. Русский наиболее опасными подтипами берегов являются абразионно-денудационные берега с обрывистым типом берегового уступа и узкими валунно-галечными пляжами восточного побережья. На о. Шкота также наиболее опасными подтипами берегов являются абразионно-денудационные берега с обрывистым типом берегового уступа и с узкими валунно-галечными пляжами.
\end{abstract}

Ключевые слова: аномальные природные процессы, береговая зона, цунами, оползни, штормовые нагоны, абразия 


\title{
THE RISK EVALUATION \\ OF THE NATURAL HAZARDOUS PROCESSES INFLUENCE \\ ON THE RUSSKY AND SHKOTA ISLAND'S COAST (PETER THE GREAT BAY, JAPAN SEA)
}

\author{
Lebedev I.I. \\ Pacific Geographical Institute FEB RAS, Vladivostok
}

\begin{abstract}
Annotation. The coastal zone researching is an important direction of geomorphology. In this zone is existed many hazardous natural processes. Coastal zone is a most important contact geosystem, where interacting different types of a nature use. In common, very important to investigate this zone for more correcting choice of optimal way of its solution. One of the main limited factors, that confine it are hazardous natural processes. Very limited number of scientists concentrates on hazardous anomalous natural processes estimation. It is revealed a scorecard method of potential hazard of natural processes influence on the Russky and Shkota coastal zone. It is given the coastal typology of Russky and Shkota islands. It is dedicated four coast types and twelve coast subtypes in Russky island. It is identified four coast types and eight coast subtypes in Shkota island. It is explicated a number of permeable intervals. This indicator is equal to relation between coastal length and geodesic line that connect both termination of a coast. Are examined special aspects of a hazardous natural processes influence (tsunami, storm surges, landslides, avalanches, abrasion) on Russky and Shkota Island's coast. These processes diffuse on both islands in full degree. Tsunami segregate on eastern island's coast, storm surges manifest on all stretch of island's coasts. Landslides and avalanches concentrate dispersily on both islands. By the use scorecard method from 1 to 3 , where 1 is a process availability, but 3 is a potential hazard (for landslides and avalanches), it is revealed the most hazardous types and subtypes of island's coasts. The most hazardous subtypes of coasts for Russky Island are abrasion and denudation coasts with a steep type of coastal bench and narrow boulder and gravel beaches of eastern coast. The most hazardous subtypes of coasts for Shkota Island also are abrasion and denudation coasts with a steep type of coastal bench and narrow boulder and gravel beaches.
\end{abstract}

Key words: anomalous natural processes, coastal zone, tsunami, landslides, storm surges, abrasion

Протяженность береговой линии Приморского края составляет приблизительно 1500 км [1]. Побережье характеризуется наиболее интенсивным хозяйственным освоением. Берега южной части региона являются наиболее освоенной частью Дальнего Востока. В непосредственной близости от южного побережья Приморья находится ряд островов, которые заселены достаточно неравномерно. На многих из них практически не ведется какая-либо антропогенная деятельность. Крупнейшим островом Приморского края является остров Русский. С юга к нему примыкает и соединяется аккумулятивной 
формой (томболо) о. Шкота. Развитие этих островов регламентируется генеральным планом развития Владивостокского городского округа от 12.02.2018 г. Согласно функциональному зонированию, большая часть восточной территории о. Русский будет отдана под рекреационное природопользование [5]. Южная зона островов Русский и Шкота будут использоваться в качестве территорий с особым режимом посещения (военные земли).

Для проведения оценки воздействия опасных природных процессов на побережье необходимо, в первую очередь, установить типологию береговой зоны. Мелкомасштабная классификация берегов островов осуществлялась на основе типологии по степени переработанности [6]. На основе полевых исследований, дешифрирования данных дистанционного зондирования, топографических и тематических карт, проведено картографирование типов берегов в масштабе 1:25000. Коэффициент расчлененности определялся как отношение между длиной берега и длины, соединяющей его концы геодезической линии [8]. Используя балльную систему оценки каждого опасного природного процесса (абразия, цунами, штормовые нагоны, оползни и обвалы), были выявлены наиболее опасные типы и подтипы берегов. Сила проявления процесса измерялась от 1 (присутствует) до 3 (потенциальная опасность (для оползней и обвалов)).

Остров Русский является одной из точек роста Приморского края. Он занимает площадь 97,6 км² и административно входит в состав Владивостокского городского округа. Вся территория острова относится к горному классу ландшафтов [4]. На острове преобладает низкогорный рельеф с высотами до 290 м и с довольно обширными участками холмисто-увалистого выположенного останцово-денудационного рельефа, разделяющего отдельные вершины или удлиненные массивы [7]. На острове можно выделить несколько типов природопользования: землепользование, водопользование, прибрежно-морское [2], а также рекреационное. Остров Шкота располагается в 0,5 км к югу от о. Русский. Площадь острова составляет примерно

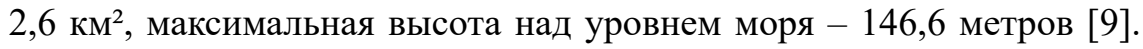
Почти $82 \%$ острова приходится на низкогорный подкласс, 12,35\% - на прибрежный подкласс ландшафтов. В северной части острова представлен пляжевый аккумулятивный на песчано-галечных прибрежных отложениях без растительного и почвенного покровов ландшафт. Сложены острова преимущественно нижне- и верхнепермскими вул- 
каническими комплексами [11]. Рельеф острова низкогорный с развитием локальных террасовидных участков в прибрежной зоне. Остров Шкота достаточно активно использовался в XX в. для военных нужд. В настоящее время все объекты заброшены [3].

На побережье о. Русский выделено 4 типа и 12 подтипов берегов. Общая длина берегов острова составляет 133,88 км. Абразионный тип берега протягивается на 44,25 км (33,05 \%) и является преобладающим типом берега на острове, $\mathrm{K}_{\text {и }}$ (коэффициент изрезанности) = 1,15. Абразионно-денудационные берега выявлены на протяжении 46,7 км $(34,88 \%) ; K_{\text {и }}=1,04$. Берег с обрывистым и крутым береговым уступом распространен, в основном, на востоке и юге острова и протягивается на 2,83 км. Берег с крутым береговым уступом встречается на всем протяжении острова фрагментарно и имеет длину 43,87 км. Аккумулятивный тип берега протягивается на 24,22 км (18,09\%) и локализуется на побережье таких бухт, как Парис, Ахлестышева, Богдановича, Островная, Боярин, Филипповского, Новик; $\mathrm{K}_{\text {и }}=1,49$. Техногенные берега выявлены на протяжении 12,54 км (9,36 \%) и занимают территорию пирсов, стоянок для судов, пляжей у населенных пунктов и т.д., $\mathrm{K}_{\text {и }}=1,43$.

Длина береговой линии о. Шкота - 9,43 км. На острове выделено 4 типа и 8 подтипов берегов. На острове преобладает абразионно-денудационный тип берега, и его общая длина составляет 6,82 км $(59 \%), K_{и}=1,1$. Берег с обрывистыми и крутыми береговыми уступами выражен на востоке, юго-западе острова и имеет длину 2,14 км. Берега с крутым береговым уступом протягиваются на 3,28 км, и локализуются на севере, западе и (фрагментарно) на востоке острова. Абразионные берега протягиваются на 2,45 км (27,64 \%), $\mathrm{K}_{\text {и }}=1,18$. Аккумулятивные берега присутствуют только на севере острова в виде косы, соединяющейся с о. Русский. Длина этого типа берега $-1,4$ км (11,67\% от общей длины всех берегов), $\mathrm{K}_{\text {и }}=1,77$. На острове также локально распространен техногенный берег в форме заброшенных чанов для засолки рыбы. Этот тип берега протягивается на 0,16 км (1,69\% от общей протяженности всех берегов острова), $K_{\text {и }}=1,14$.

Цунами на побережье островов достаточно редкое событие, как и на всей территории Приморья. Сразу после цунами 1983 г. обследование было проведено на восточном побережье о. Русский, величина заплеска составляла от 0,5 м (бух. Парис) до 1,5 м (бухты Аякс и Житкова), зона затопления достигала 36 м [10]. При воздействии 
такого заплеска могут пострадать такие объекты, как Кампус ДВФУ (набережная), рекреанты на близлежащих местах отдыха (пляж Аякс, пляж бух. Парис). На побережье бух. Спокойная дальность затопления цунами 1833 года составила 50 м. Она же является популярным местом отдыха.

Штормовые нагоны и тайфуны являются постоянными явлениями на берегах залива Петра Великого. Их формирование сводится к прохождению над акваторией моря циклонов 4-х типов. В среднем в XX веке на побережье вблизи г. Владивостока высота штормового нагона составляла 50 см [12]. Действие тайфунов приводит к активизации экзогенных процессов на о. Русский и о. Шкота. Они способствуют более быстрому сползанию рыхлых пород по склону. Хотя влияние мощных циклонов прослеживается чаще всего лишь с июля по сентябрь, оно может привести к серьезным последствиям для природопользователей, расположенных на побережье. Обвалы приурочены к берегам с обрывистым и крутым береговым уступом. Опасность оползней на о. Русский проявляется в основном на побережье. В восточной части острова присутствуют многочисленные оползневые склоны от оз. Ахлестышева до п-ова Вятлина. Они приурочены к обрывистым и крутым береговым уступам. С ними связана угроза ведению хозяйственной деятельности. Активная абразия проявляется дисперсно в разных частях острова. Обвалы и оползни выражены на побережье о. Шкота достаточно отчетливо. Наиболее распространены обвалы на востоке и юго-востоке острова. Оползни наиболее выражены на востоке. Абразия выражена в основном на востоке.

На основе балльной оценки (табл. 1) было установлено, что наиболее опасными подтипами берегов на о. Русский являются абразионные с обрывистым типом берегового уступа и с узкими и преимущественно валунными пляжами, а также абразионно-денудационные берега с обрывистыми и крутыми береговыми уступами и со средней ширины галечно-гравийно-песчаными пляжами. Средней степенью опасности характеризуются абразионные берега с обрывистым береговым уступом без пляжей, а также абразионно-денудационные берега с крутым береговым уступом и со средней ширины и широкими пляжами. Низкая степень опасности характерна для абразионно-денудационного типа берега с крутым типом берегового уступа и узким галечно-гравийно-песчаным пляжем, а также для аккумулятивных и техногенных берегов (рис.1). 
Таблица 1

Оценка опасности береговой зоны о. Русский

\begin{tabular}{|c|l|c|}
\hline Номер & \multicolumn{1}{|c|}{ Подтип берега } & $\begin{array}{c}\text { Опасность } \\
\text { (в баллах) }\end{array}$ \\
\hline 1.1 & $\begin{array}{l}\text { абразионный берег с обрывистым береговым уступом } \\
\text { без пляжа }\end{array}$ & 6,61 \\
\hline 1.2 & $\begin{array}{l}\text { абразионный берег с обрывистым береговым уступом и } \\
\text { с узким и преимущественно валунным пляжем }\end{array}$ & 6,95 \\
\hline 2.1 & $\begin{array}{l}\text { абразионно-денудационный берег с обрывистым и } \\
\text { крутым береговым уступом и с узким и валунно- } \\
\text { галечным пляжем }\end{array}$ & 6,83 \\
\hline 2.2 & $\begin{array}{l}\text { абразионно-денудационный берег с обрывистым и } \\
\text { крутым береговым уступом и средней ширины галечно- } \\
\text { гравийно-песчаным пляжем }\end{array}$ & 6,88 \\
\hline 2.3 & $\begin{array}{l}\text { абразионно-денудационный берег с крутым береговым } \\
\text { уступом и с узким галечно-гравийно-песчаным пляжем }\end{array}$ & 6,17 \\
\hline 2.4 & $\begin{array}{l}\text { абразионно-денудационный берег с крутым береговым } \\
\text { уступом и со средней ширины галечно-гравийно- } \\
\text { песчаным пляжем }\end{array}$ & 6,34 \\
\hline 2.5 & $\begin{array}{l}\text { абразионно-денудационный с крутым береговым } \\
\text { уступом и широким галечно-гравийно-песчаным } \\
\text { пляжем }\end{array}$ & 6,125 \\
\hline 3.1 & $\begin{array}{l}\text { аккумулятивный берег с галечно-гравийно-песчаным } \\
\text { пляжем полного профиля }\end{array}$ & 6,24 \\
\hline 3.2 & $\begin{array}{l}\text { аккумулятивный берег с гравийно-песчаным пляжем в } \\
\text { приустьевых областях }\end{array}$ & $\begin{array}{l}\text { техногенный берег с широким галечно-гравийно- } \\
\text { песчаным пляжем }\end{array}$ \\
\hline техногенный берег без пляжа & 6,15 \\
\hline техногенный берег с узким и галечно-гравийно- \\
\hline песаным пляжем
\end{tabular}

Выявлено, что наиболее опасным подтипом берега о. Шкота при проявлении опасных природных процессов является абразионный берег с обрывистым береговым уступом и с узким и преимущественно валунным пляжем. Также повышенной опасностью характеризуется абразионный берег с обрывистым береговым уступом без пляжа и абразионно-денудационный берег с обрывистым и крутым береговым уступом и средней ширины галечно-гравийно-песчаным пляжем. Более низкой степени опасности подвержены абразионно-денудационные берега с крутым береговым уступом и с узким галечно-гравийно-песчаным пляжем, а также аккумулятивные и техногенные берега (табл. 2, рис. 2). 


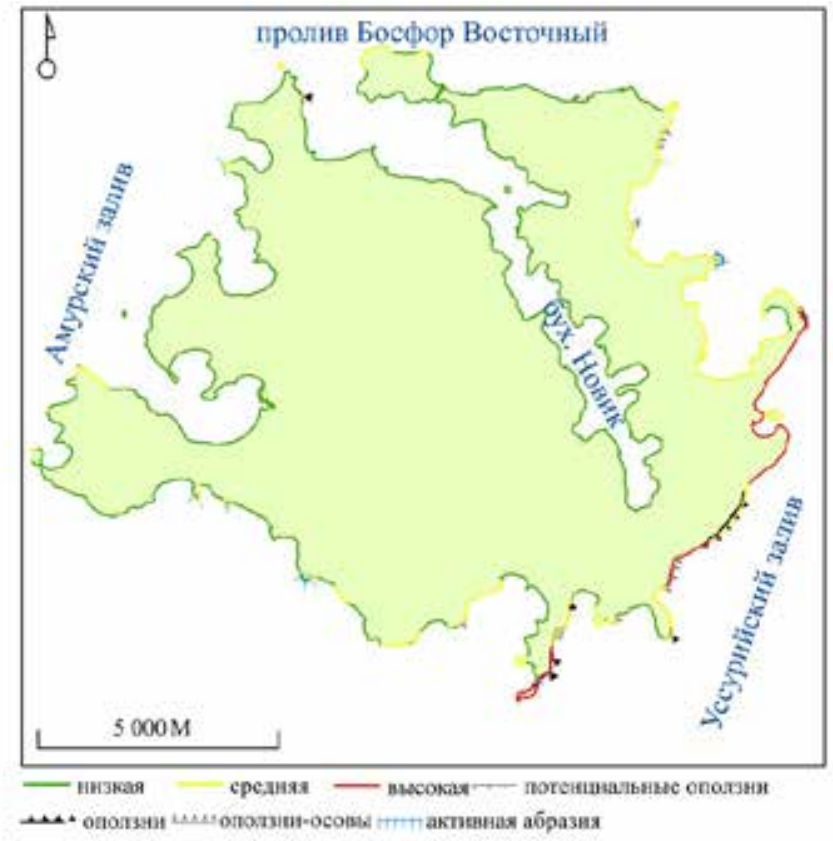

Рис. 1. Опасность береговой зоны о. Русский

Таблица 2

Оценка опасности береговой зоны о. Шкота при воздействии опасных природных процессов

\begin{tabular}{|c|l|c|}
\hline Номер & \multicolumn{1}{|c|}{ Подтип берега } & $\begin{array}{c}\text { Опасность } \\
\text { в баллах }\end{array}$ \\
\hline 1.1 & $\begin{array}{l}\text { абразионный берег с обрывистым береговым } \\
\text { уступом без пляжа }\end{array}$ & 9,13 \\
\hline 1.2 & $\begin{array}{l}\text { абразионный берег с обрывистым береговым } \\
\text { уступом и с узким и преимущественно валунным } \\
\text { пляжем }\end{array}$ & 8,4 \\
\hline 2.1 & $\begin{array}{l}\text { абразионно-денудационный берег с обрывистым и } \\
\text { крутым береговым уступом и с узким и валунно- } \\
\text { галечным пляжем }\end{array}$ & 8,88 \\
\hline 2.2 & $\begin{array}{l}\text { абразионно-денудационный берег с обрывистым } \\
\text { и крутым береговым уступом и средней ширины } \\
\text { галечно-гравийно-песчаным пляжем }\end{array}$ & 6,66 \\
\hline 2.3 & $\begin{array}{l}\text { абразионно-денудационный берег с крутым } \\
\text { береговым уступом и с узким галечно-гравийно- } \\
\text { песчаным пляжем }\end{array}$ & \\
\hline
\end{tabular}


Окончание табл. 2

\begin{tabular}{|c|l|c|}
\hline Номер & \multicolumn{1}{|c|}{ Подтип берега } & $\begin{array}{c}\text { Опасность } \\
\text { в баллах }\end{array}$ \\
\hline 2.4 & $\begin{array}{l}\text { абразионно-денудационный берег с крутым } \\
\text { береговым уступом и со средней ширины галечно- } \\
\text { гравийно-песчаным пляжем }\end{array}$ & 7,33 \\
\hline 3.1 & $\begin{array}{l}\text { аккумулятивный берег с галечно-гравийно-песчаным } \\
\text { пляжем полного профиля }\end{array}$ & 7 \\
\hline 4.1 & техногенный берег без пляжа & 7 \\
\hline
\end{tabular}

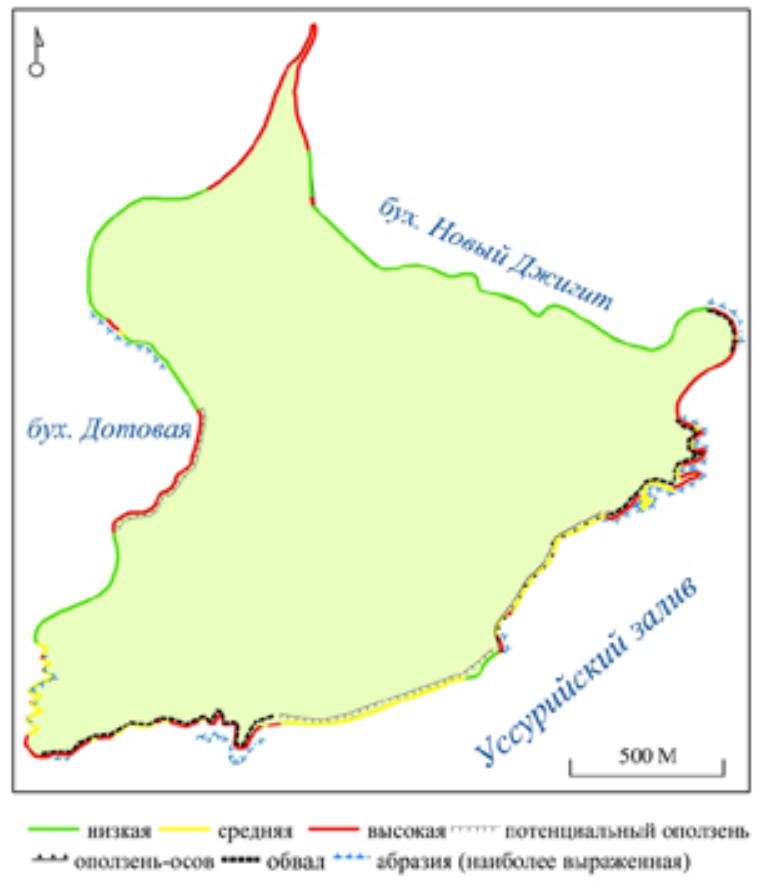

Рис. 2. Опасность береговой зоны о. Шкота при воздействии опасных природных процессов

Таким образом, были выявлены наиболее опасные подтипы берегов на островах Русский и Шкота. Во многом самым опасным подтипом берега для обоих островов является абразионный с обрывистым береговым уступом и с узким и преимущественно валунным пляжем. Также для обоих островов наименее опасными типами берегов являются аккумулятивный и техногенный. Для островов характерно 
наличие таких опасных природных процессов, как проявление цунами, штормовых нагонов, абразии, оползней и обвалов. Необходимо учитывать, что именно на восточном побережье о. Русский, где берег наиболее опасен, находится основные объекты инфраструктуры и очень активна рекреационная деятельность. На о. Шкота, также очень опасным является восточный берег, где также останавливаются рекреанты.

Работа выполнена при финансовой поддержке комплексной программы фундаментальных исследований “Дальний Восток”, проект ВАНТ 18-010, и проекта РНФ № 18-77-00001 "Устойчивое природопользование островных геосистем в условиях реализации программ опережающего социально-экономического развития (на примере островов юга Дальнего Востока России)".

Научный руководитель: д.г.н., г.н.с. лаб. палеогеографии и геоморфологии ТИГ ДВО РАН Разжигаева Н.Г.

\section{Литература}

1. Бакланов П.Я., Зонов Ю.Б., Романов М.Т. География Приморского края. Владивосток: Уссури, 1997. $180 \mathrm{c.}$

2. Бакланов П.Я. Бровко П.Ф., Воробьева Т.Ф., Говорушко С.М., Зонов Ю.Б., Каракин В.П., Качур А.Н., Ланкин А.С., Мошков А.В., Романов М.Т., Шейнгауз А.С. Региональное природопользование: методы изучения, оценки, управления. М.: Логос, 2002. $160 \mathrm{c}$.

3. Ганзей К.С., Пшеничникова Н.Ф., Киселева А.Г., Родникова И.М., Юрченко С.М. Влияние рекреационной деятельности на геосистемы островов залива Петра Великого // Безопасность природопользования в условиях устойчивого развития [Электронный ресурс]: материалы II Международной научно-практической конференции. Иркутск: Издательство ИГУ, 2018. С. 313-321.

4. Ганзей К.С., Киселева А.Г., Пшеничникова Н.Ф. Ландшафты острова Русский (залив Петра Великого, Японское море): пространственная организация и особенности функционирования // Успехи современного естествознания. 2016. № 6. С. 138-143

5. Генеральный план Владивостокского городского округа [Электронный ресурс] // Владивосток: официальный сайт администрации города. - Режим доступа: http://old.vlc.ru/life_city/architecture_and_construction/general_plan/ (дата обращения: 13.04.2019 г.).

6. Ионин А.С., Каплин П.А., Медведев В.С. Классификация типов берегов земного шара // Труды океанографической комиссии АН СССР. 1961. Т. 12. С. 7-29.

7. Короткий А.М. Колебания уровня Японского моря и ландшафты прибрежной зоны (этапы развития и тенденции) // Вестник ДВО РАН. 1994. № 3. С. 22-42.

8. Морская геоморфология. Терминологический справочник. Береговая зона: процессы, понятия, определения / Науч. ред. В.П. Зенковича и Б.А. Попова. М.: Мысль, 1980. 280 с. 
9. Остров Шкота [Электронный ресурс] // Shamora.info - Режим доступа: http:// shamora.info/Шкота-остров/ (дата обращения: 08.04.2019 г.).

10. Полякова А.М. Цунами в Приморье 26 мая 1983 г. и его последствия. Владивосток: ТОИ ДВНЦ АН СССР, 1988. 36 с.

11. Преловский В.И., Короткий А.М., Пузанова И.Ю., Саболдашев С.А. Бассейновый принцип формирования рекреационных систем Приморья. Владивосток: ДВО PAH, 1996. $150 \mathrm{c}$.

12. Шевченко Г.В., Любицкий Ю.В., Като Л.Н. Проявление штормовых нагонов в южной части острова Сахалин: препринт. Южно-Сахалинск: ИМГиГ ДВО РАН, 1994. $44 \mathrm{c}$.

\section{References}

1. Baklanov P.Ya., Zonov Yu.B., Romanov M.T. Geografiya Primorskogo kraya [Geography of Primorsky krai]. Vladivostok, Ussuri Publ., 1997. 180 p.

2. Baklanov P.Ya., Brovko P.F., Vorobyeva T.F., Govorushko S.M., Zonov Yu.B., Karakin V.P., Kachur A.N., Lankin A.S., Moshkov A.V., Romanov M.T., Sheingauz A.S. Regionalnoe prirodopolzovaniye: metody izucheniya, otsenki, upravleniya [Regional nature use: methods of learning, estimation, management]. Moscow, Logos Publ., 2002. 160 p.

3. Ganzey K.S., Pshenichnikova N.F., Kiseleva A.G., Rodnikova I.M., Yurchenko S.M. [Recreational activity influence on The Peter Great Bay gulf's island's geosystems]. Materialy II Mezhdunarodnoy nauchno-prakticheskoy konferentsii "Bezopasnost zhiznedeyatelnosti v usloviyakh ustoychivogo razvitiya" [Abstracts of II International research and practice conference "Safe of activity in sustainable development conditions"]. Irkutsk: IGU Publ., 2018, pp. 313-321 (In Russian).

4. Ganzey K.S., Kiseleova A.G., Pshenichnikova N.F. Landshafty ostrova Russkiy (zaliv Petra Velikogo, Yaponskoye more): prostranstvennaya organizatsiya i osobennosti funktsionirovaniya [Landscapes of Russky Island (Peter the Great Bay, Sea of Japan): spatial organization and functioning peculiarities]. Uspekhi sovremennogo yestestvoznaniya - Advances in current natural sciences, 2016, no. 6, pp. 138-143.

5. Generalnyy plan Vladivostokskogo gorodskogo okruga [General scheme of Vladivostok urban district]. Available at: http://old.vlc.ru/life_city/architecture_and_construction/general_plan/ (accessed: 13.04.2019).

6. Ionin A.S., Kaplin P.A., Medvedev V.S. [Classification of coast types on the Earth]. Trudy okeanograficheskoy komissii AN SSSR [Proceedings of Oceanographic section of Academy of sciences of USSR]. 1961. T. 12, pp. 7-29. (In Russian).

7. Korotkiy A.M. Kolebaniya urovnya Yaponskogo morya I landshafty pribrezhnoy zony (etapy razvitiya I tendetsii) [Fluctuation of Japan Sea level and landscapes of coastal zone (stages of development and tendencies)]. Vestnik DVO RAN-Bulletin of FEB RAS, 1994, no. 3, pp. 22-42.

8. Morskaya geomorfologiya. Terminologicheskiy spravochnik. Beregovaya zona: protsessy, ponyatiya, opredeleniya [Sea geomorphology. Terminological dictionary. Coastal zone: processes, notions, definitions]. Eds.: Zenkovich V.P., Popov B.A. Moscow, Mysl Publ., 1980, 280 p.

9. Ostrov Shkota [Shkota Island]. Available at: http://shamora.info/Шкота-остров/ (accessed: 08.04.2019). 
10. Polyakova A.M. Tsunami v Primorye 26 maya 1983 goda I ego posledstviya [Tsunami in Primorye at May, 26 in 1983 and its consequences]. Vladivostok, POI FEB of Academy of USSR, 1988. $36 \mathrm{p}$.

11. Prelovskiy V.I., Korotkiy A.M., Puzanova I.Yu., Saboldashev S.A. Basseynovyy printsip formirovaniya rekreatsionnykh sistem Primorya [Regional concept of recreational systems formation in Primorye]. Vladivostok, FEB RAS, 1996. 150 p.

12. Shevchenko G.V., Lyubitskiy Yu.V., Kato L.N. Proyavleniye shtormovykh nagonov v yuzhnoy chasti ostrova Sakhalin: preprint [Storm surge's influence in southern part of Sakhalin island: preprint]. Yuzhno-Sakhalinsk, IMGIG DVO RAN, 1994. 44 p. 